\title{
Molecular Origin of Biologically Accelerated Mineralization of Hydroxyapatite on Bacterial Cellulose for More Robust Nanocomposites
}

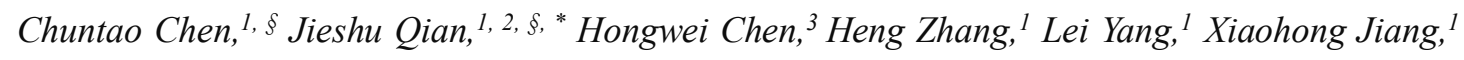
Xuan Zhang, ${ }^{2}$ Xiaoyu Li, ${ }^{4}$ Jing Ma, ${ }^{3,}{ }^{*}$ Dongping Sun ${ }^{l, ~ *}$

${ }^{1}$ Institute of Chemicobiology and Functional Materials, School of Chemistry and Chemical Engineering, Nanjing University of Science and Technology, 200 Xiao Ling Wei, Nanjing, 210094, China

2 Jiangsu Key Laboratory of Chemical Pollution Control and Resources Reuse, School of Environmental and Biological Engineering, Nanjing University of Science and Technology, 200 Xiao Ling Wei, Nanjing, 210094, China

${ }^{3}$ School of Chemistry and Chemical Engineering, Key Laboratory of Mesoscopic Chemistry of Ministry of Education, Key Laboratory of Mesoscopic Chemistry of Ministry of Education, Institute of Theoretical and Computational Chemistry, Nanjing University, 163 Xianlin Road, Nanjing, 210023, China

${ }^{4}$ Department of Polymer Materials, School of Materials Science and Engineering, Beijing Institute of Technology, Beijing, 100081, China

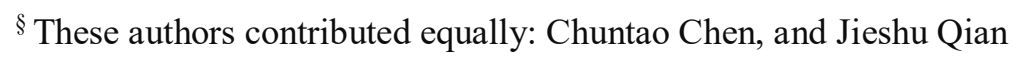

${ }^{*}$ Correspondence author:

qianjieshu@njust.edu.cn (J. Q.) majing@nju.edu.cn (J. M.), and hysdp@,njust.edu.cn (D. S.) 


\section{EXPERIMENTAL SECTION}

Materials. Acetobacter xylinum NUST4.2 was used in this study. HS (Hestrin and Schramm) basic medium $\left(\mathrm{g} \mathrm{L}^{-1}\right)$ consisting of glucose 25 , yeast extract 5 , peptone 5 , citric acid monohydrate 1.2 and $\mathrm{Na}_{2} \mathrm{HPO}_{4} 2.7$ was used. All fermentation media were sterilized at $121{ }^{\circ} \mathrm{C}$ for $30 \mathrm{~min}$. The seed broth and fermentation broth in the culture were incubated statically at $28{ }^{\circ} \mathrm{C}$ for $24 \mathrm{~h}$ at $\mathrm{pH}$ 6.0. Before fermentation, the strain was first cultured in a seed medium for $24 \mathrm{~h}$, containing $20 \mathrm{~g}$ carbon source, $5 \mathrm{~g}$ nitrogen source, $3 \mathrm{~g} \mathrm{Na}_{2} \mathrm{HPO}_{4}, 1 \mathrm{~g} \mathrm{KH}_{2} \mathrm{PO}_{4}, 0.02 \mathrm{~g} \mathrm{MgCl}_{2}, 0.02 \mathrm{~g} \mathrm{CaCl}_{2}$, and $0.0015 \mathrm{~g}$ amino benzoic acid per litre, and with initial $\mathrm{pH}$ adjusted to 6.0. Afterward, the seed cultures were centrifuged for $10 \mathrm{~min}$ at $8,000 \mathrm{r} / \mathrm{min}$, and the precipitate was washed three times using a 0.9 wt. $\% \mathrm{NaCl}$ solution for the subsequent use.

Preparation of b-BC/HAp. The as-prepared seed was inoculated in fresh HS medium containing $0.015 \mathrm{M} \mathrm{CaCl}_{2}$ and cultured at $30{ }^{\circ} \mathrm{C}$ for $24 \mathrm{~h}$ with shaking rate of $150 \mathrm{r} / \mathrm{min}$. An isovolumetric $1.0 \times \mathrm{SBF}$ solution was then added into for static fermentation after $24 \mathrm{~h}$, which is the timing for the fastest stage of bacteria growth in this system. The $\mathrm{pH}$ value was then adjusted to be between 7-7.4 using phosphate buffer and kept almost constant during the mineralizaiton process. The SBF solution was prepared according to the Cüuneyt Tas procedure ${ }^{1}$. The chemical composition of SBF solution is listed in Table S1 in SI. For the need of ceasing the experiments, the floating solid was removed and treated with sodium hydroxide solution (4 wt. \%) at $80{ }^{\circ} \mathrm{C}$ for 2 $\mathrm{h}$, followed by washing with deionized water and freeze dried before XRD and XPS characterization.

Preparation of c-BC/HAp. Mature $\mathrm{BC}$ samples were immersed in $0.015 \mathrm{M} \mathrm{CaCl}_{2}$ solution at $30{ }^{\circ} \mathrm{C}$ for $24 \mathrm{~d}$, followed by soaking in a $10 \times \mathrm{SBF}$ solution at $37^{\circ} \mathrm{C}$ for 1 to 10 d. Finally, the obtained samples were rinsed with deionized water and freeze dried before characterization.

Characterization. The infrared spectra were obtained using a Nicolet iS10 FTIR instrument (Thermo Fisher Scientific, USA) with a wavenumber range from 500 to $4000 \mathrm{~cm}^{-1}$ by accumulating 32 scans at a resolution of $4 \mathrm{~cm}^{-1}$. XPS spectra were 
obtained using a RBD upgraded PHI-5000C ESCA system (Perkin Elmer) with Mg K radiation $(h=1253.6 \mathrm{eV})$. XRD spectra were recorded on a D8 Advance diffractometer (Bruker, Germany) using $\mathrm{Cu} K \alpha$ radiation $(\lambda=0.154 \mathrm{~nm})$ at $40 \mathrm{kV}$ and $40 \mathrm{~mA}$ with a scanning range of $5-50^{\circ}$. Scanning electron microscopy (SEM) images were taken using a Zeiss electron microscope (Supra 55, Carl Zeiss). Transmission electron microscope (TEM) images were taken by a JEM-2100 (Japan) at $200 \mathrm{kV}$. The samples were fixed with gluteraldehyde, stained by $\mathrm{OsO}_{4}$, and washed by water before microscopy examination. The surface morphology and Young's modulus of dry samples were determined by PeakForce tapping mode atomic force microscopy (AFM, MultiMode V, Veeco) at room temperature. Silicon cantilever NSC-36 C (Mikromasch Inc) having pyramidal tips with $9 \pm 2 \mathrm{~nm}$ nominal radii of curvature and cantilever spring constant of $2 \mathrm{~N} \mathrm{~m}^{-1}$ were used. The Young's modulus of the samples were calculated using the Hertzian model. ${ }^{2}$ Poisson's ratio (n) is set to 0.5 and parabolic geometry of the indenter is set.

Statistics. Dots in figures report values obtained from independent replicates unless otherwise noted. Data in Figure 4k and S8 in SI are expressed as means \pm standard deviation. Each experiment was repeated at least three times.

Theoretical calculations for results in Figure 5 and Table S3. The binding strength of $\mathrm{Ca}^{2+}(\mathrm{M})$ with the ligand $(\mathrm{Y})$ such as $6 \mathrm{glc}$ was calculated by using density functional theory (DFT) with the implicit polarizable continuum model (PCM) at the level M062X/6-311+g(d,p) within the Gaussian 16 package $^{3}$. The binding free energy $\left(G_{\text {bind }}\right)$ of complex was derived from the following equation:

$$
G_{\mathrm{bind}}=G_{\mathrm{MY}}+6 \times G_{\mathrm{wt}}-\mathrm{G}_{\mathrm{Y}}-G_{\mathrm{M}(\mathrm{wt})_{6}}
$$

Where $\mathrm{M}=\mathrm{Ca}^{2+}, \mathrm{Y}=6 \mathrm{glc}, \mathrm{G}_{\mathrm{wt}}$ represents the gibbs free energy of water molecule. A negative value of $G_{\text {bind }}$ of a complex indicates that this compound is thermodynamically stable.

Theoretical calculations for results in Figure S11-S16, Table S4-S6. To study the mineralization process of calcium phosphate solution on cellulose, we carry out the molecular dynamics (MD) simulations by using AMBER16 simulation package ${ }^{4}$. The 
GAFF2 force field is used for the cellulose molecule, $\mathrm{HPO}_{4}{ }^{2-}$ and $\mathrm{HCO}_{3}{ }^{-}$ions. After optimization with using the density functional theory (DFT) method at B3LYP/6$311 \mathrm{~g}(\mathrm{~d}, \mathrm{p}), \mathrm{B} 3 \mathrm{LYP} / 6-311+\mathrm{g}(\mathrm{d}, \mathrm{p})$ and B3LYP/6-311+g(d,p) levels within the Gaussian 16 program $^{3}$, their partial charges are fitted with the restricted electrostatic potential (RESP) method ${ }^{5}$. At first, the minimization and heating procedure at constant volume from $100 \mathrm{~K}$ to $300 \mathrm{~K}$ are performed, and then run the $200 \mathrm{~ns}$ MD simulations with the NPT ensemble at $300 \mathrm{~K}$ and 1 bar. The temperature is maintained by Langevin dynamics ${ }^{6}$ with the collision frequency of $1 \mathrm{ps}^{-1}$, and the integration time step is set to 1 fs. The direct spatial nonbonded cutoff of $8.0 \AA$ is used. Moreover, we calculate the binding free energy of $\mathrm{HCO}_{3}{ }^{-}, \mathrm{HPO}_{4}{ }^{2-}$ and $\mathrm{Ca}^{2+}, \mathrm{Mg}^{2+}$ ions at the level of $\mathrm{DFT} / \mathrm{M} 062 \mathrm{X} / 6-311+\mathrm{g}(\mathrm{d}, \mathrm{p})$ to observe which combination mode is the most favorable. The binding free energy $\left(G_{\text {bind }}\right)$ is obtained by calculating the free energy difference between the compound $\mathrm{M}(\mathrm{Y})_{\mathrm{n}}$ and $\mathrm{Y}$ ions $\left(\mathrm{Y}=\mathrm{HCO}_{3}{ }^{-}\right.$or $\mathrm{HPO}_{4}{ }^{2-}, \mathrm{n}=1$ or 2$)$, which is shown as

$$
\begin{aligned}
& G_{\mathrm{bind}}=G_{\mathrm{MHPO}_{4}}+G_{(\mathrm{wt})_{6}}-G_{\mathrm{HPO}_{4}^{2-}}-G_{M(\mathrm{wt})_{6}} \\
& G_{\mathrm{bind}}=G_{M\left(\mathrm{HCO}_{3}\right)_{2}}+G_{(\mathrm{wt})_{6}}-2 G_{\mathrm{HCO}_{3}^{-}}-G_{M(\mathrm{wt})_{6}}
\end{aligned}
$$

Where $\mathrm{M}=\mathrm{Ca}^{2+}$ and $\mathrm{Mg}^{2+}, G_{(\mathrm{wt}) 6}$ represents the Gibbs free energy of water cluster of six $\mathrm{H}_{2} \mathrm{O}$ molecule. 


\section{Supporting Figures and Accompanying Discussion}
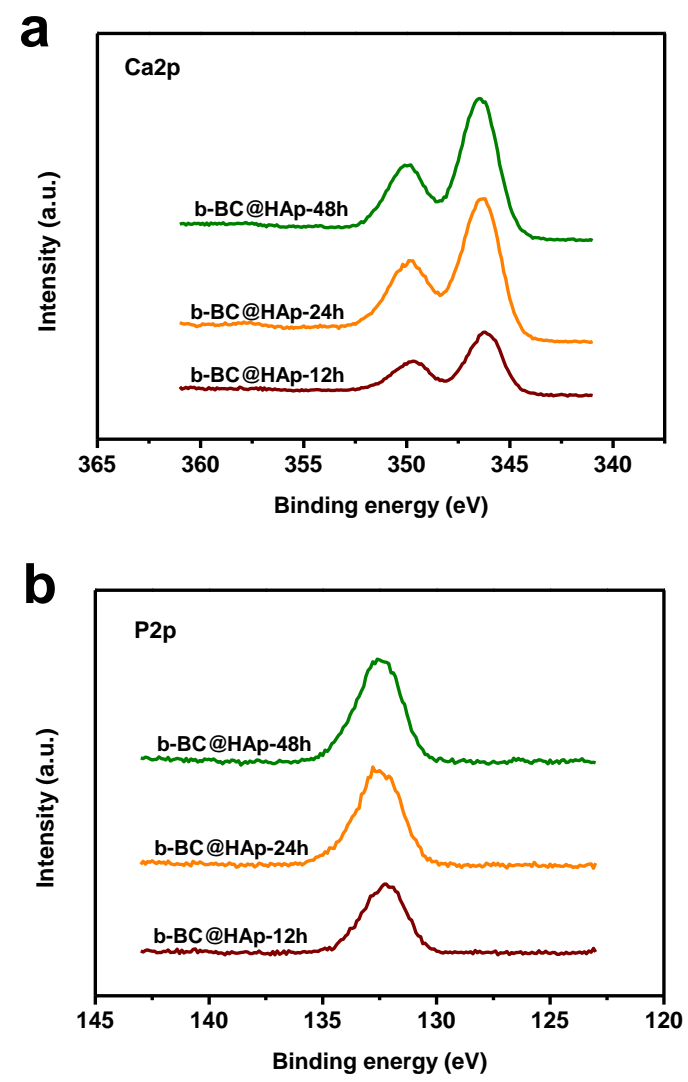

Figure S1. XPS (a) Ca 2p and (b) P 2p spectra of b-BC@HAp composites obtained under different fermentation time, i.e. $12 \mathrm{~h}, 24 \mathrm{~h}$, and $48 \mathrm{~h}$. 

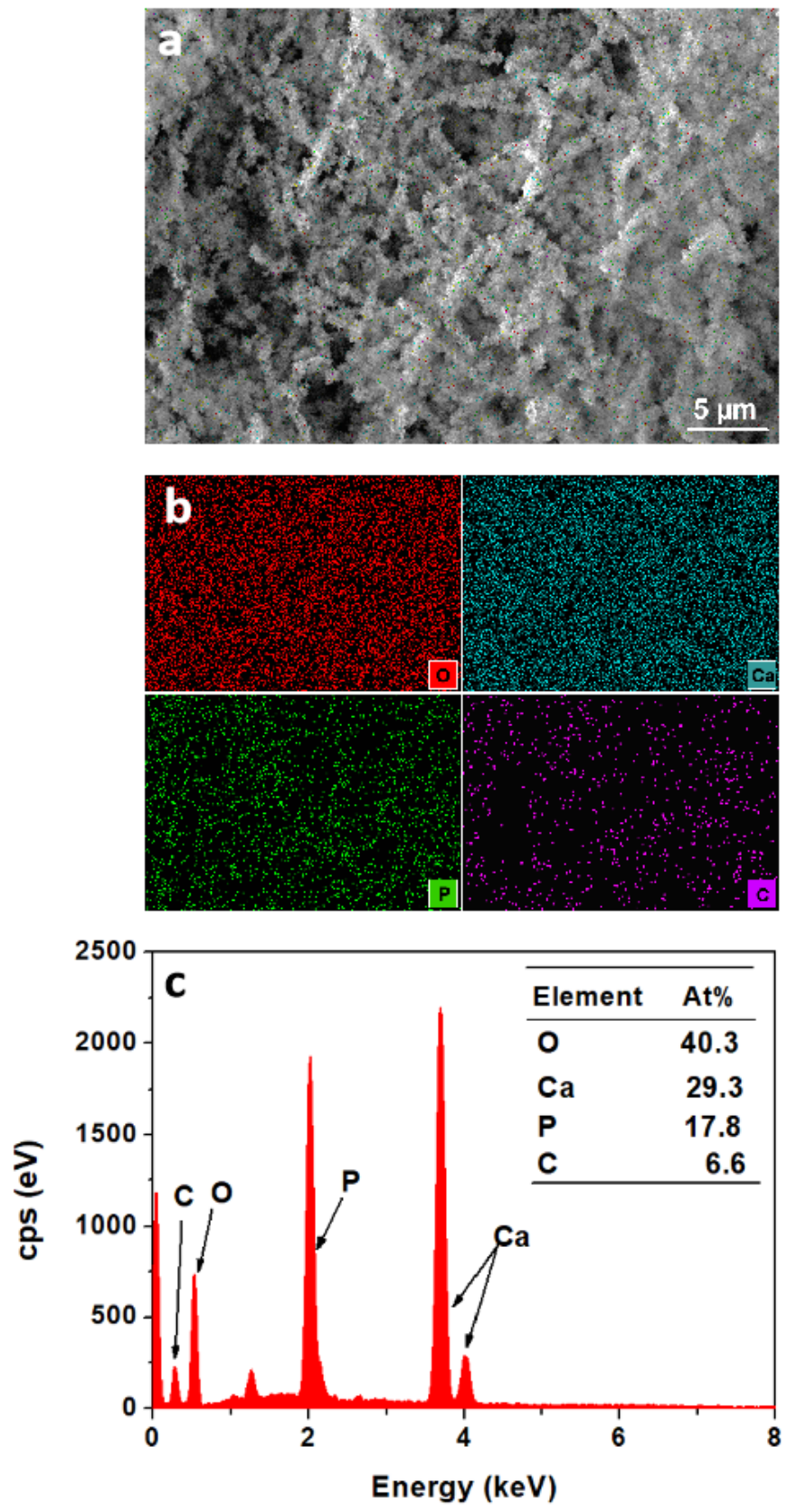

Figure S2. (a) SEM global view image, (b) the corresponding elemental mapping, and (c) EDS results showing the elemental fraction of the b-BC@HAp-24h sample. 

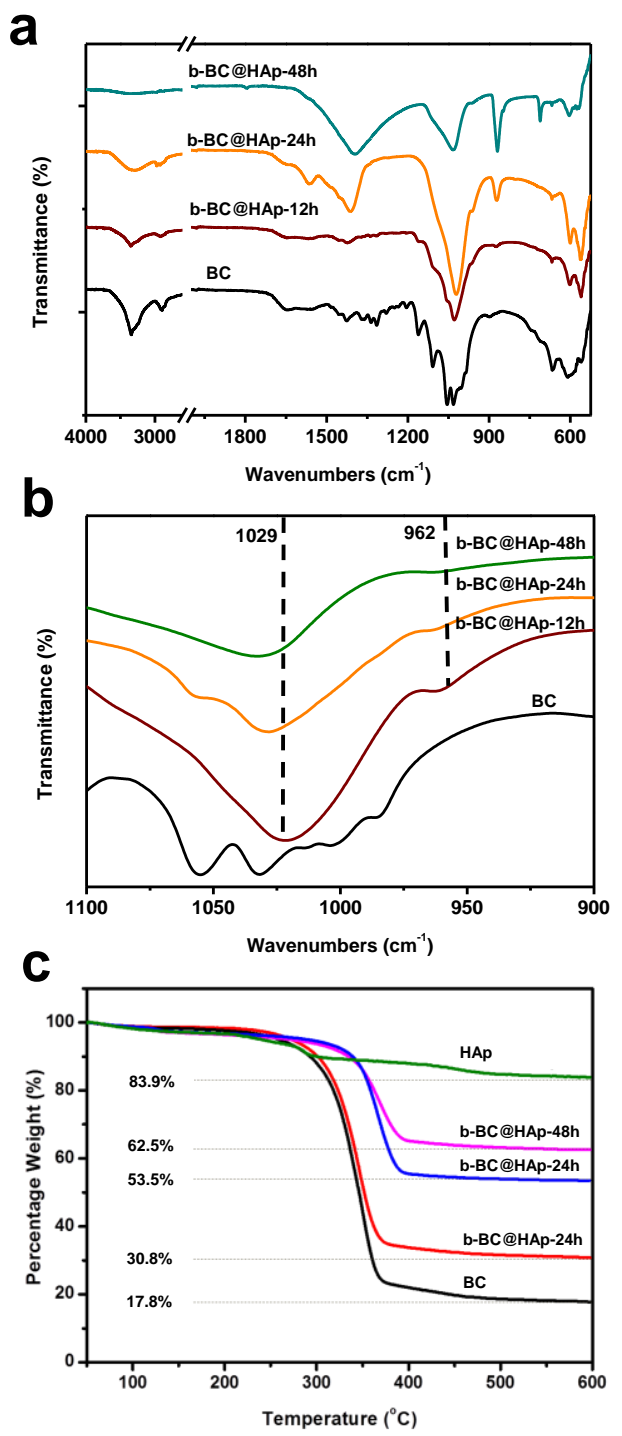

Figure S3. FT-IR (a) whole and (b) regional spectra of BC and b-BC@HAp composites obtained under different fermentation time, i.e. $12 \mathrm{~h}, 24 \mathrm{~h}$, and 48h; (c) TGA curves of BC, HAp, and bBC@HAp samples with mineralization of 12h, 24h, or 48h.

The FT-IR spectra in Figure S3a and S3b show that, in comparison to the pristine BC, the b-BC@HAp composites exhibit new adsorption peaks at 1029 and $962 \mathrm{~cm}^{-1}$, which are attributed to the stretching vibration of $\mathrm{PO}_{4}{ }^{3-}$ ions. The peak at $962 \mathrm{~cm}^{-1}$ is located on the shoulder of the $1029 \mathrm{~cm}^{-1}$ peak, instead of a sharp band in typical HAp spectra, presumably due to the poor crystallinity of HAp formed in this case ${ }^{1}$. 

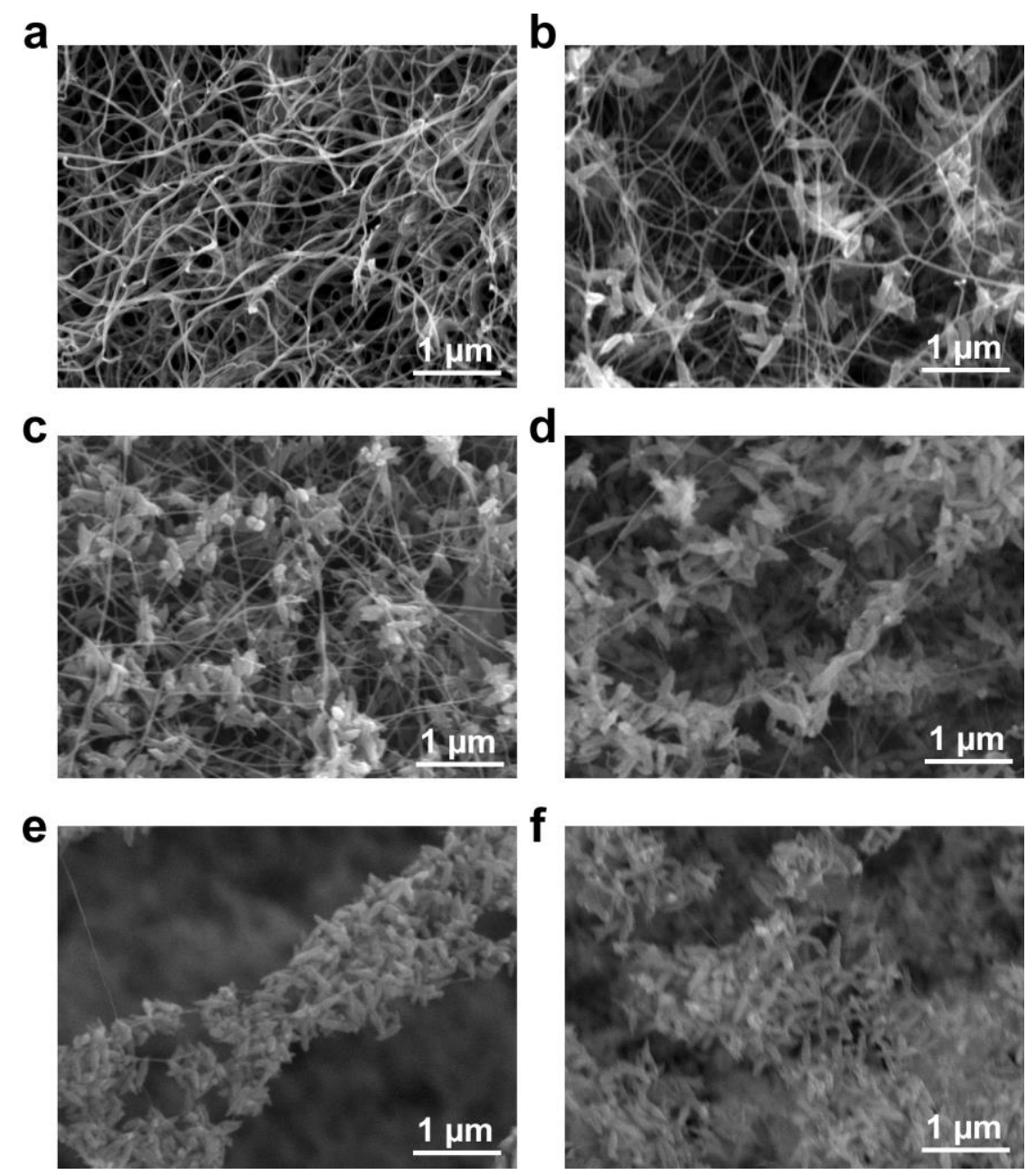

Figure S4. Representative SEM images of (a) BC and (b to f) b-BC@HAp composites with increasing fermentation time, (b) $6 \mathrm{~h}$, (c) $12 \mathrm{~h}$, (d) $24 \mathrm{~h}$, (e) $36 \mathrm{~h}$, and (f) $48 \mathrm{~h}$. 


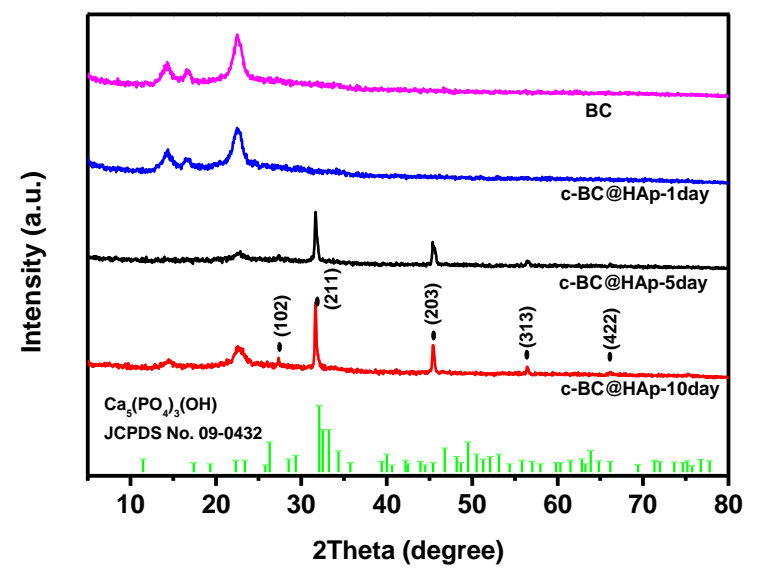

Figure S5. XRD patterns of BC and c-BC@HAp composites with different mineralization time. 

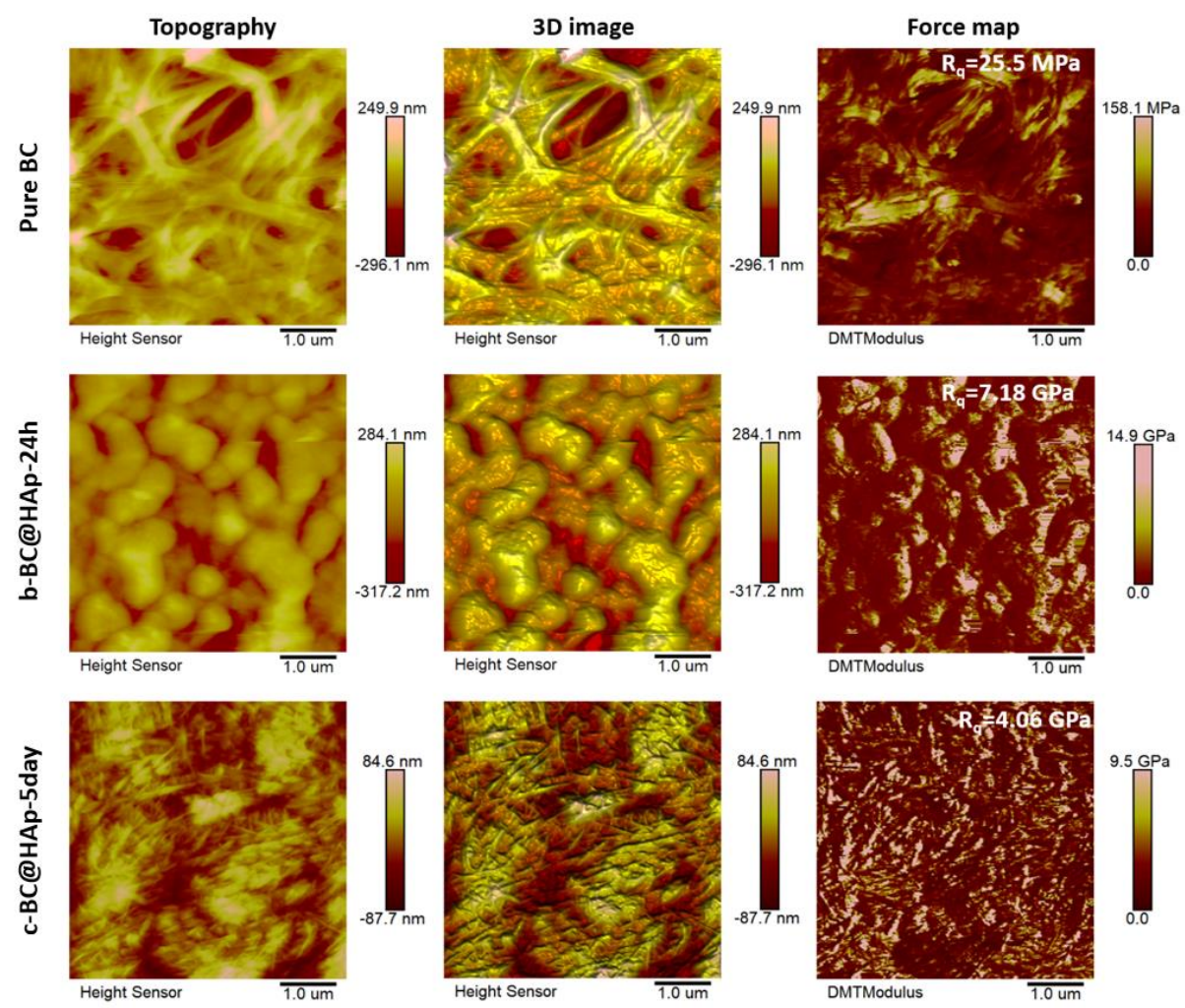

Figure S6. AFM PeakForce tapping mode compressive topography, 3D image, and force mapping of pure BC, b-BC@HAp-24h, and c-BC@HAp-5day. 

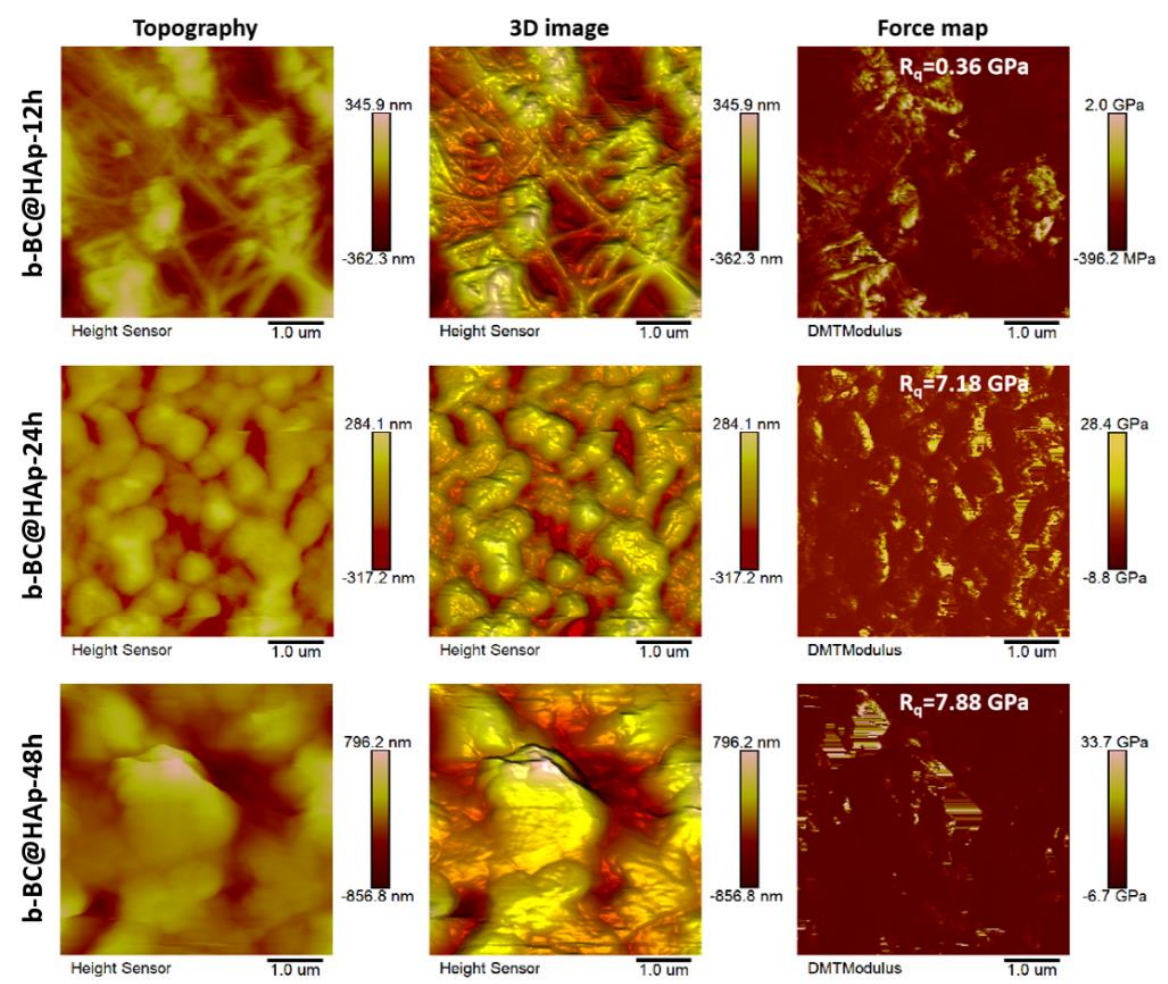

Figure S7. AFM contact-mode compressive topography, 3D image, and force mapping of b-BC@HAp-12, b-BC@HAp-24h, and b-BC@HAp-48h. 


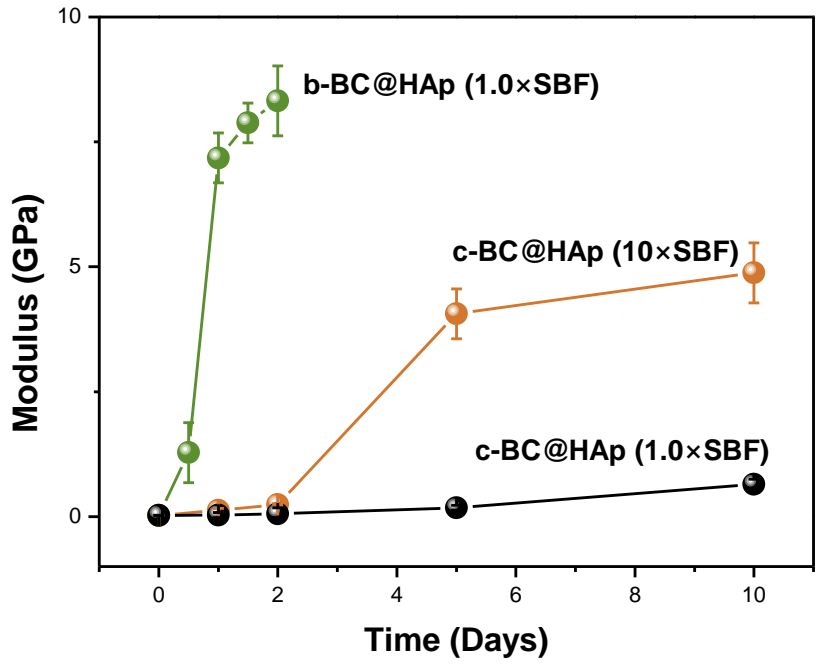

Figure S8. Evolution of Young's modulus of $(1 \times \mathrm{SBF}$ and $10 \times \mathrm{SBF})$ composites over mineralization time. 

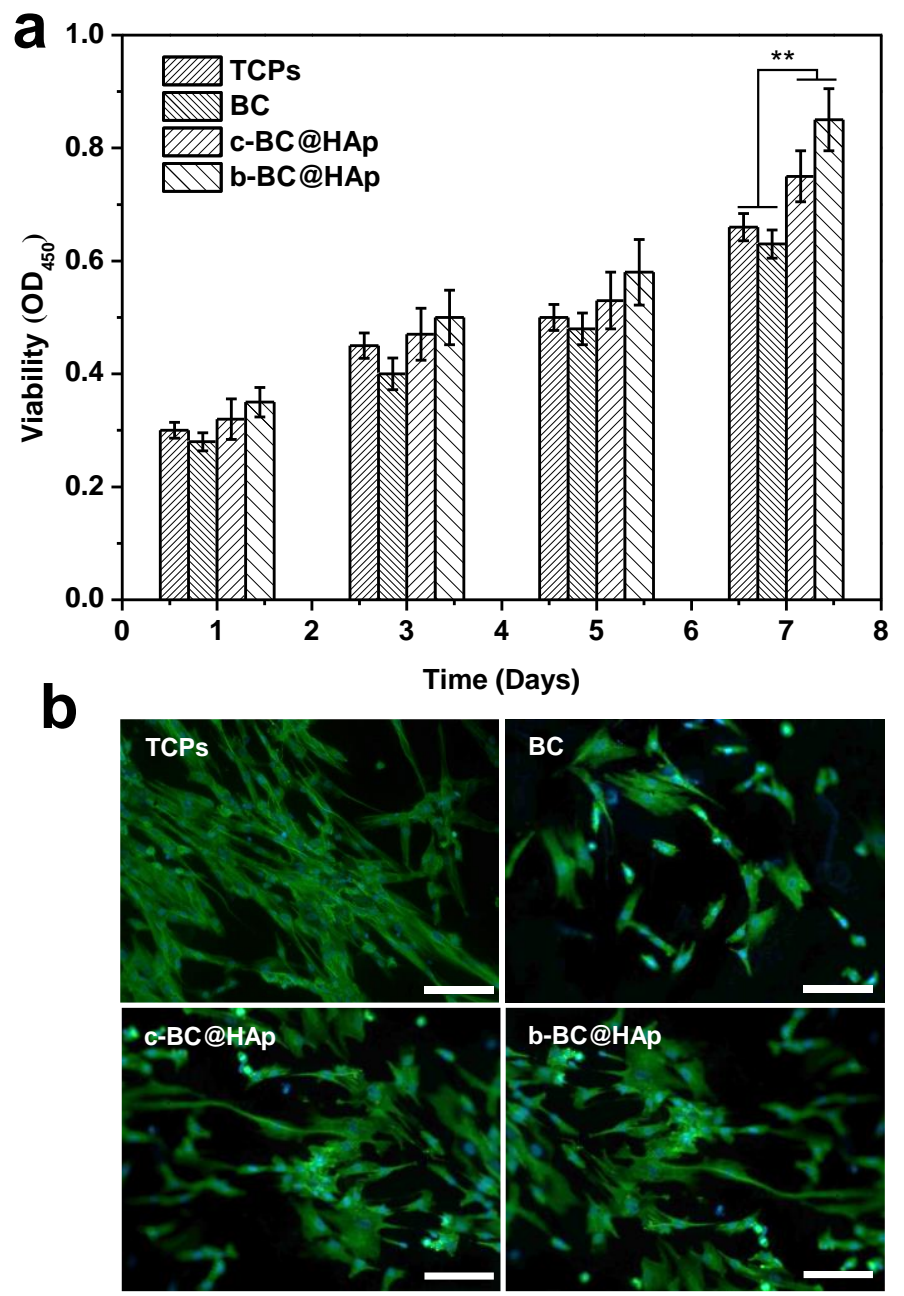

Figure S9. (a) Comparison of the hMSCs cells on different scaffolds surfaces, number of samples $\mathrm{N}=4$; (b) Fluorescence images of hMSCs cultured on TCPs, BC nanofibers, bBC@HAp $(1 \times \mathrm{SBF})$ and c-BC@HAp substrates at day 7, scale bar $=50 \mu \mathrm{m},{ }^{*} p p<0.01$. Immunostaining the cytoskeleton of hMSCs cells with FITC-labelled anti-Actin antibody was carried out by following the well-documented methods. ${ }^{7,8}$ Cell viabilities cultured on the substrates were examined using the standard methyl thiazolyl tetrazolium (MTT) assay. ${ }^{9}$ The fluorescent images were taken by a fluorescence microscope (Olympus) configured with Nuance CCD. 
a

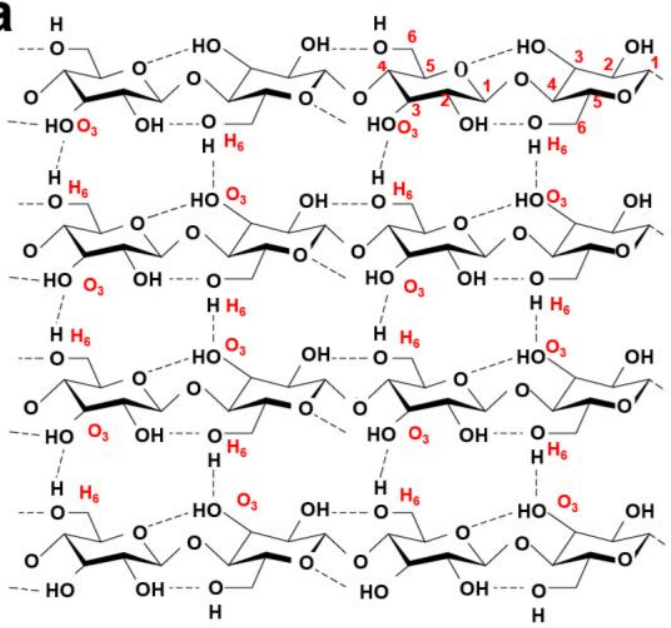

b

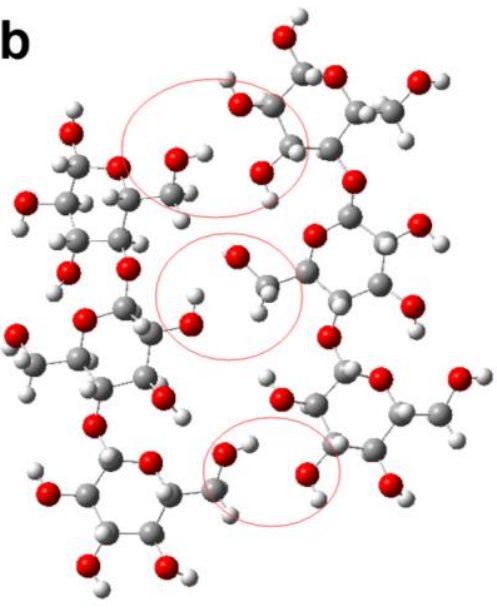

Figure S10. The molecule structural formula (a) and structure model (b) of BC, showing the intermolecular hydrogen bonding between cellulose molecular chain. 
We carried out molecular dynamics (MD) calculation by using AMBER16 simulation package $^{4}$ to simulate the nucleation process of calcium phosphate on newly synthesized cellulose molecular chains by bacteria.

It can be seen from Figure S11-S14, $\mathrm{Ca}^{2+}$ and $\mathrm{HPO}_{4}{ }^{2-}$ ions are randomly distributed in the whole water box at $\mathrm{t}=0 \mathrm{~ns}$. With the evolution of simulation time, the small and loosely bound $\mathrm{CaHPO}_{4}$ clusters are formed at 100 ns. When the simulation time increases to $200 \mathrm{~ns}$, these small clusters come close to each other and aggregate into the larger clusters.

In order to estimate the whole aggregation process more qualitatively, we counted the number of $\mathrm{HPO}_{4}{ }^{2-}$ ions around calcium ions. The distance of $\mathrm{Ca}-\mathrm{O}\left(\mathrm{HPO}_{4}{ }^{2-}\right)$ in the first solvation shell is achieved by calculating their radial distribution functions (RDF, see Figure S15a), in which the cutoff distance between them is set to $3 \AA$ (the first local minimum of corresponding RDF). It can be inferred from Figure $\mathrm{S} 15 \mathrm{~b}$ that the $\mathrm{Ca}^{2+}$ ions are surrounded by only four $\mathrm{HPO}_{4}{ }^{2-}$ ions without cellulose molecule (black line), while the fifth $\mathrm{HPO}_{4}{ }^{2-}$ ion combines with $\mathrm{Mg}^{2+}$ ion to form $\mathrm{MgHPO}_{4}$, which is consistent with the relative stronger binding free energies of $\mathrm{CaHPO}_{4}$ than $\mathrm{MgHPO}_{4}$. The $\mathrm{Ca}^{2+}$ ions (red line) are all covered with $\mathrm{HPO}_{4}{ }^{2-}$ ions, which indicates that the presence of cellulose can facilitate the aggregation of $\mathrm{CaHPO}_{4}$ cluster.

When we increase the concentration of $\mathrm{HPO}_{4}{ }^{2-}$ ions and $\mathrm{Ca}^{2+}$ ions in the simulated water box (blue line), the $\mathrm{Ca}^{2+}$ ions are covered with all $\mathrm{HPO}_{4}{ }^{2-}$ ions in a short time (within $30 \mathrm{~ns})$. In contrast, we not only increase the number of ions $\left(\mathrm{Ca}^{2+}\right.$ and $\left.\mathrm{HPO}_{4}{ }^{2-}\right)$, but also increase the size of the simulated water box in the fourth system, which would make those $\mathrm{HPO}_{4}{ }^{2-}$ ions and $\mathrm{Ca}^{2+}$ ions less accessible. It can be seen from Figure S15b (green line) that the $\mathrm{Ca}^{2+}$ ions are covered by $\mathrm{HPO}_{4}{ }^{2-}$ ions for a long time (within $150 \mathrm{~ns}$ ), but there is still a $\mathrm{HPO}_{4}{ }^{2-}$ ion combine with nearby $\mathrm{Mg}^{2+}$ ion to form $\mathrm{MgHPO}_{4}$, which shows that the lower concentration in larger simulation box will greatly extend the time of $\mathrm{CaHPO}_{4}$ aggregation. It can be seen from Table S4 and Table S5 from both models that compound $\mathrm{CaHPO}_{4}$ has the largest binding free energy, indicating that the combination of $\mathrm{HPO}_{4}{ }^{2-}$ and $\mathrm{Ca}^{2+}$ is more favorable than $\mathrm{MgHPO}_{4}$. In the MD 
simulations, four cellulose models are built (see Table S6), and the glucan chains ( $\beta$-Dglucose for $\left.(\mathrm{GLU})_{6}\right)$ referred to our previous work ${ }^{9}$.

Moreover, we also simulated the mineralization process in calcium phosphate solution by increasing the degree of polymerization of the cellulose ( $\beta$-D-glucose for (GLU) 8 ) and the number of glucan chains (6 glucan chains), $30 \mathrm{HPO}_{4}{ }^{2-}$ ions, $40 \mathrm{Ca}^{2+}$ ions, 100 $\mathrm{HCO}_{3}{ }^{-}$ions, $16 \mathrm{Mg}^{2+}$ ions, $48 \mathrm{Na}^{+}$ions and 7224 water molecules $\left(60 \times 60 \times 60 \AA^{3}\right)$. Before the MD simulations (Figure $\mathrm{S} 16 \mathrm{a}$ ), the distribution of $\mathrm{HPO}_{4}{ }^{2-}$ ions and $\mathrm{Ca}^{2+}$ ions and glucan chains are relatively scattered. As the simulation time increases to $200 \mathrm{~ns}$ (Figure S16b), some smaller calcium phosphate clusters begin to accumulate near glucan chains, and the glucan chains also intertwine with each other. After $400 \mathrm{~ns}$ simulations (Figure $\mathrm{S} 16 \mathrm{c}$ ), the $\mathrm{Ca}^{2+}$ ions and $\mathrm{HPO}_{4}{ }^{2-}$ ions form the larger calcium phosphate clusters in the simulated water box, which shows that the increase of the number of dispersed glucan chains causes the aggregation of calcium and phosphorus clusters. These effects are beneficial for the formation of HAp crystal nucleus, resulting in a homogeneous coating on the surface of BC nanofibers. To summarize, in this biological metabolism condition, the formation of $\mathrm{CaHPO}_{4}$ is prefered to the formation of $\mathrm{MgHPO}_{4}$. 
(a) Simulation model: without cellulose $+10 \mathrm{Ca}^{2+}+5 \mathrm{HPO}_{4}{ }^{2-}$
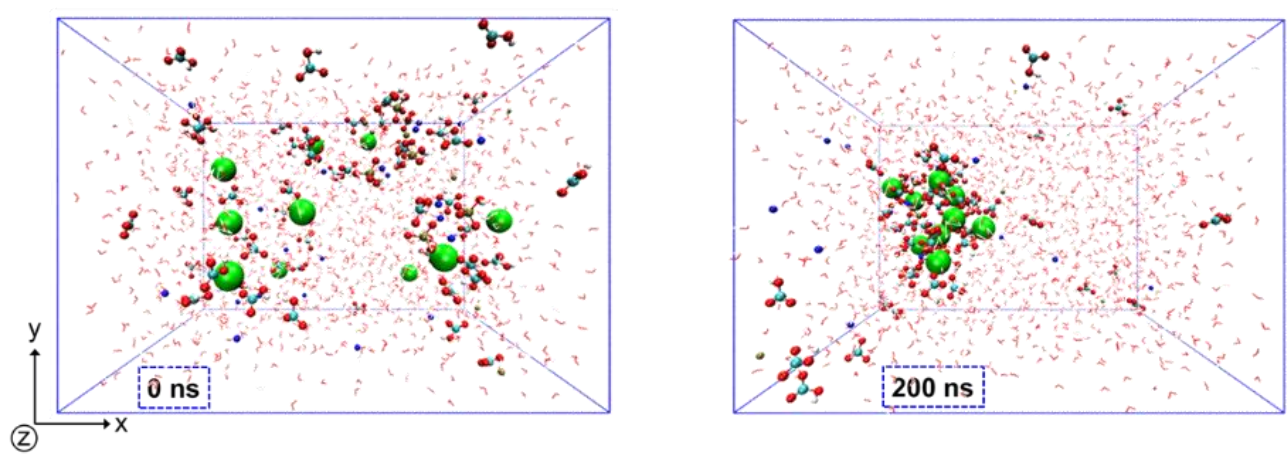

(b) Highlighted components in snapshots
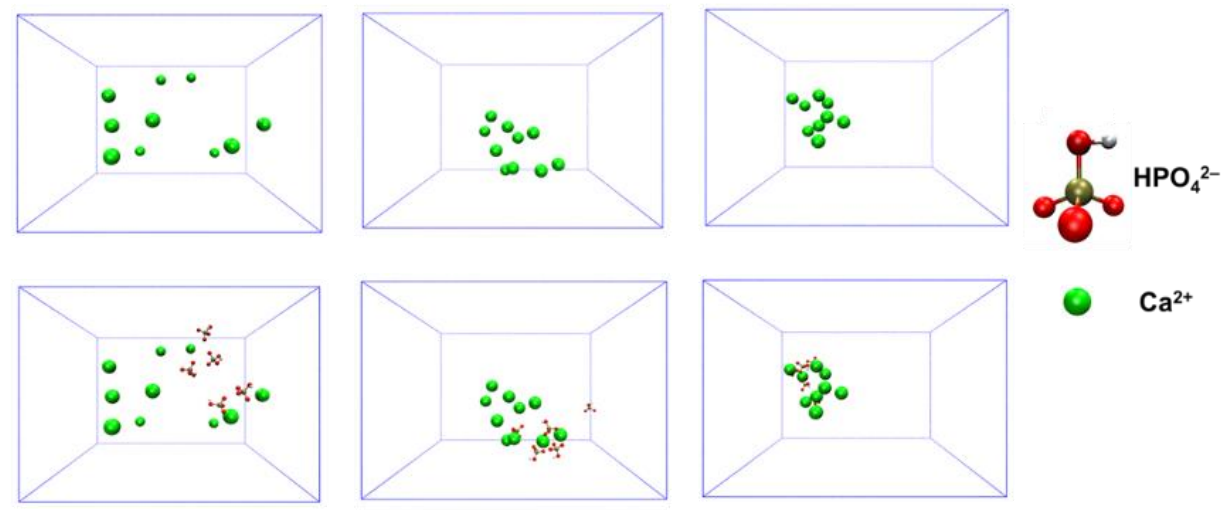

- $\mathrm{Ca}^{2+}$

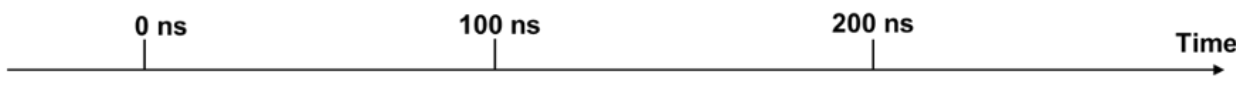

Figure S11. Snapshots of (a) explicit illustration of all ions and water molecules, (b) only $\mathrm{Ca}^{2+}$ and $\mathrm{HPO}_{4}{ }^{2-}$ ions are shown. $\mathrm{Ca}^{2+}, \mathrm{Mg}^{2+}$ and $\mathrm{Na}^{+}$ions are shown as green (VDW system), tan and blue respectively, $\mathrm{HPO}_{4}{ }^{2-}$ and $\mathrm{HCO}_{3}{ }^{-}$ions as $\mathrm{CPK}$ system and water molecules as lines model. 
(a) Simulation model: cellulose $+10 \mathrm{Ca}^{2+}+5 \mathrm{HPO}_{4}{ }^{2-}$

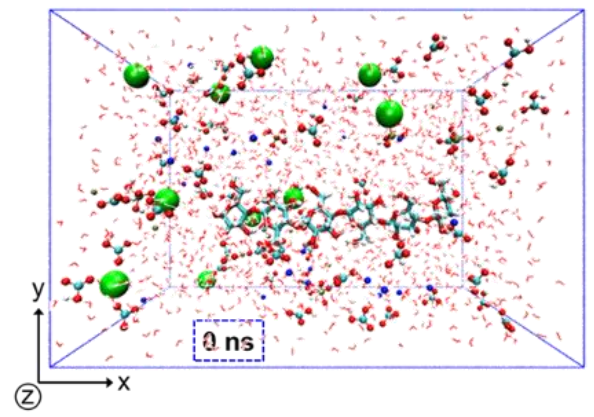

(b) Highlighted components in snapshots
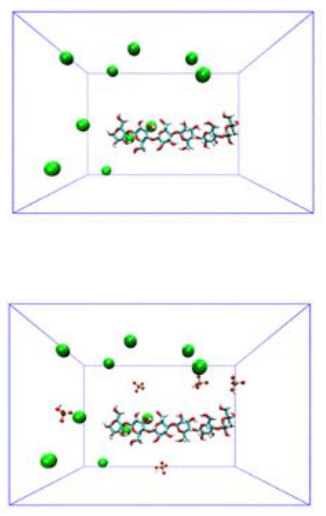

$0 \mathrm{~ns}$
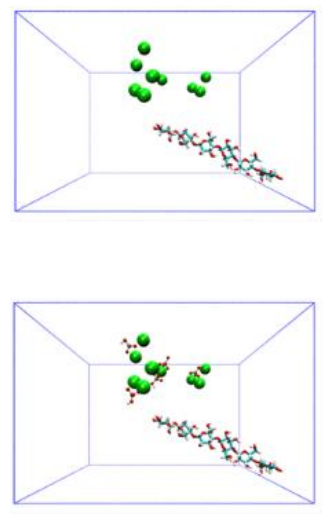

$100 \mathrm{~ns}$
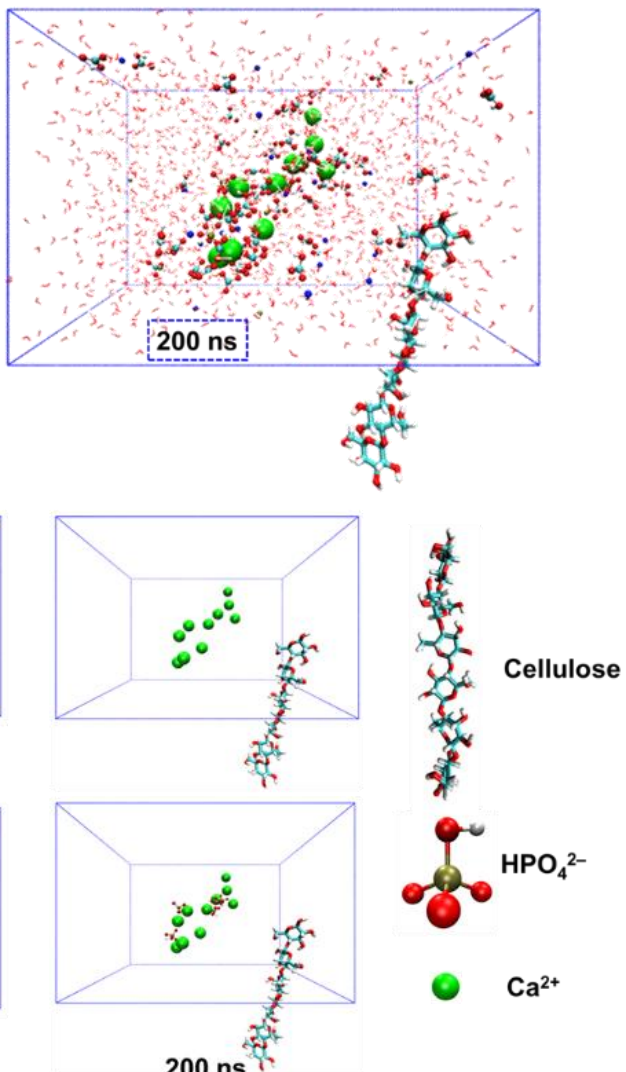

$200 \mathrm{~ns}$

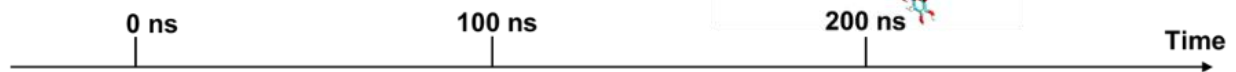

Figure S12. Snapshots of (a) explicit illustration of all ions and water molecules, (b) only cellulose molecule, $\mathrm{Ca}^{2+}$ and $\mathrm{HPO}_{4}{ }^{2-}$ ions are depicted. The cellulose molecule is located in the center of the water box ( $0 \mathrm{~ns})$ by Licorice model. 
(a) Simulation model: cellulose $+20 \mathrm{Ca}^{2+}+15 \mathrm{HPO}_{4}{ }^{2-}$
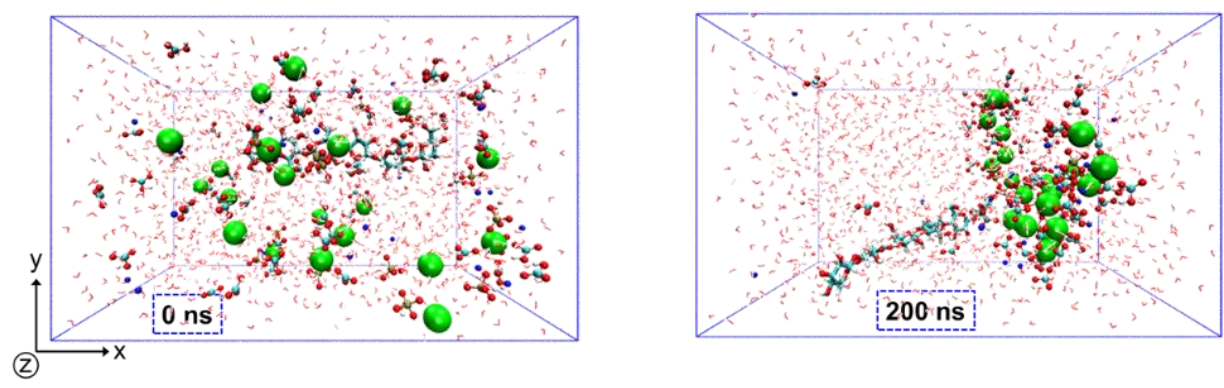

(b) Highlighted components in snapshots

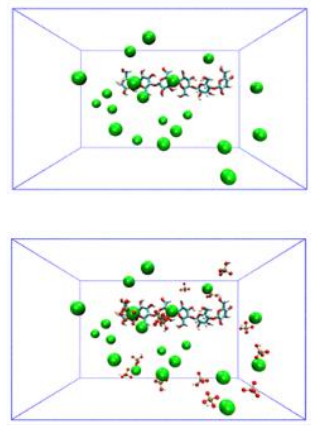

O ns
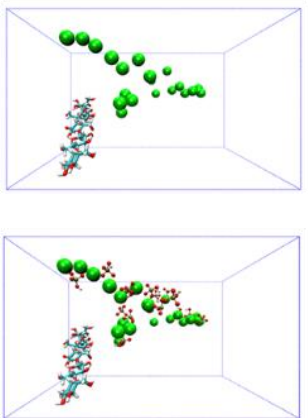

$100 \mathrm{~ns}$
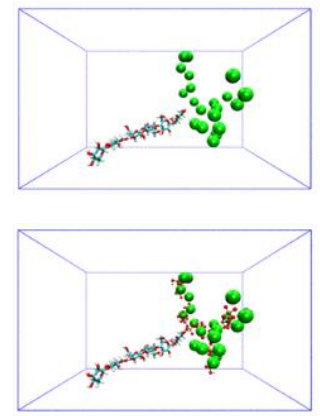

$200 \mathrm{~ns}$
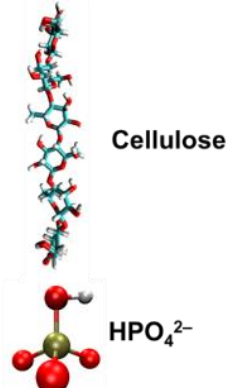

- $\mathrm{Ca}^{2+}$

Time

Figure S13. Snapshots of (a) explicit illustration of all ions and water molecules, (b) only cellulose molecule, $\mathrm{Ca}^{2+}$ and $\mathrm{HPO}_{4}{ }^{2-}$ ions are depicted. The cellulose molecule is located in the center of the water box ( $0 \mathrm{~ns})$ by Licorice model. 
(a) Simulation model: cellulose $+20 \mathrm{Ca}^{2+}+15 \mathrm{HPO}_{4}{ }^{2-}$ (larger box $)$
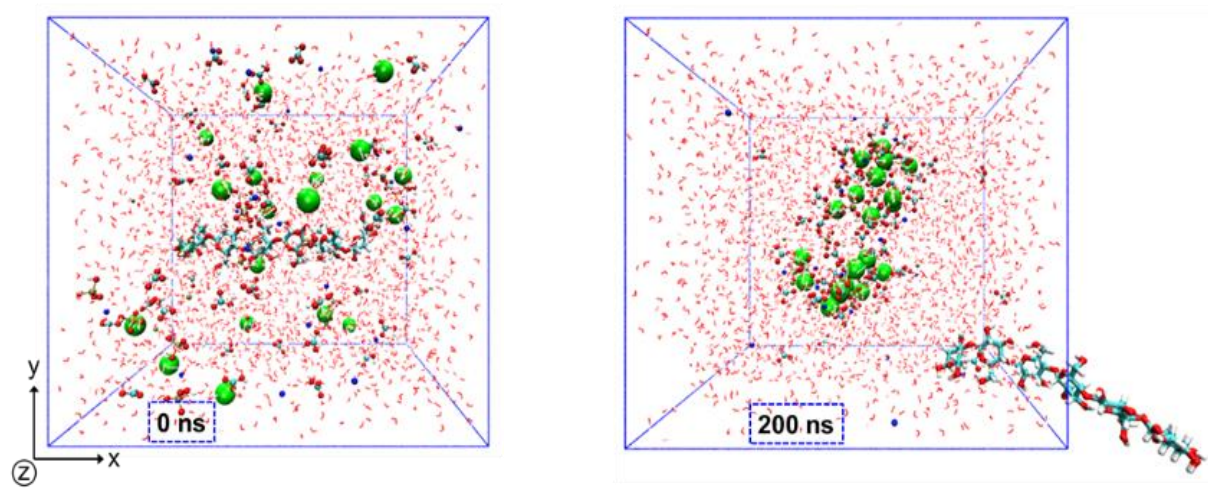

(b) Highlighted components in snapshots
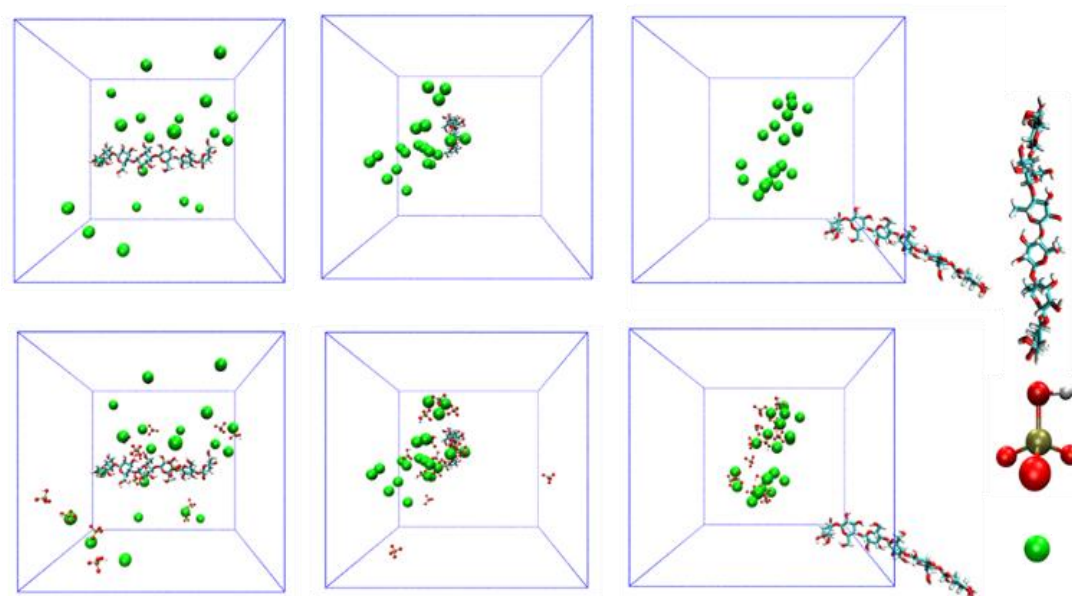

Cellulose
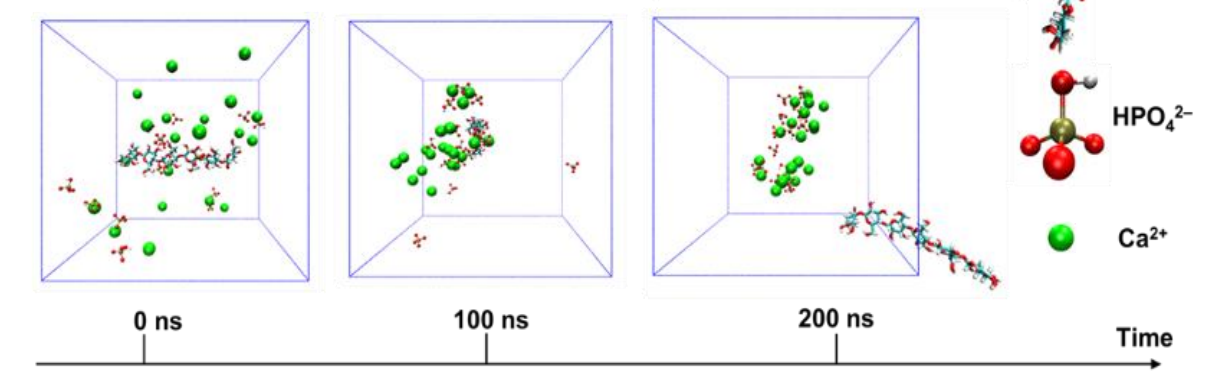

- $\mathrm{Ca}^{2+}$

Figure 14. Snapshots of (a) explicit illustration of all ions and water molecules, (b) only $\mathrm{Ca}^{2+}$ and $\mathrm{HPO}_{4}{ }^{2-}$ ions are shown. $\mathrm{Ca}^{2+}, \mathrm{Mg}^{2+}$ and $\mathrm{Na}^{+}$ions are shown as green (VDW system), tan and blue respectively, $\mathrm{HPO}_{4}{ }^{2-}$ and $\mathrm{HCO}_{3}{ }^{-}$ions as $\mathrm{CPK}$ system and water molecules as lines system. 


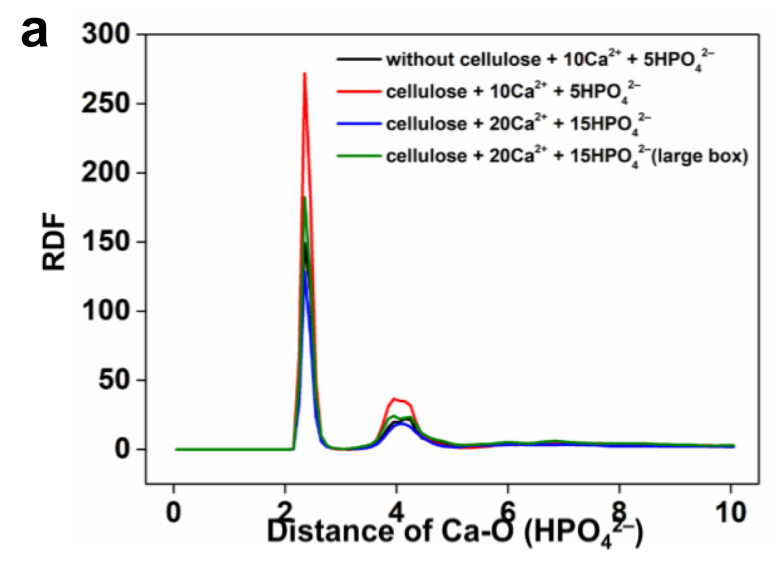

b

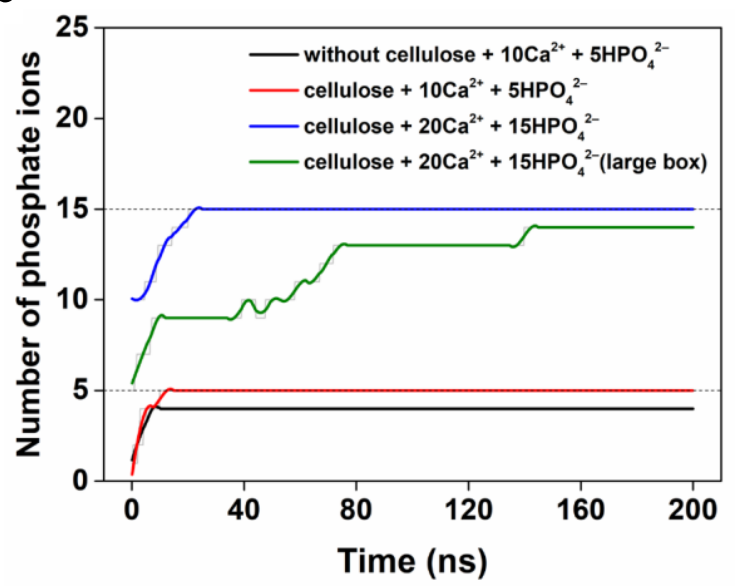

Figure S15. (a) Radial distribution functions (RDF) for the Ca-O $\left(\mathrm{HPO}_{4}{ }^{2-}\right)$ in the studied systems; (b) The number of $\mathrm{HPO}_{4}{ }^{2-}$ ions around $\mathrm{Ca}^{2+}$ with the cutoff distance of $3 \AA$ between $\mathrm{O}\left(\mathrm{HPO}_{4}{ }^{2-}\right)$ and $\mathrm{Ca}^{2+}$ ion as a function of simulation time. The values corresponding to the dotted lines are 5 and 15 , respectively. 
(a) Simulation time (0 ns)

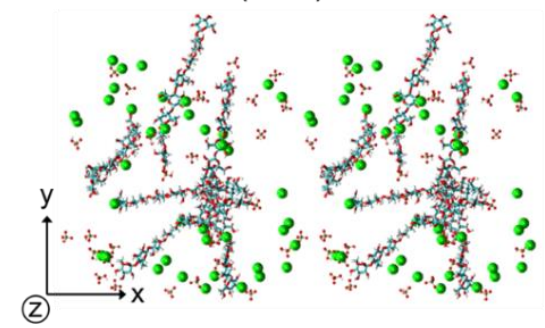

(b) Simulation time (200 ns)

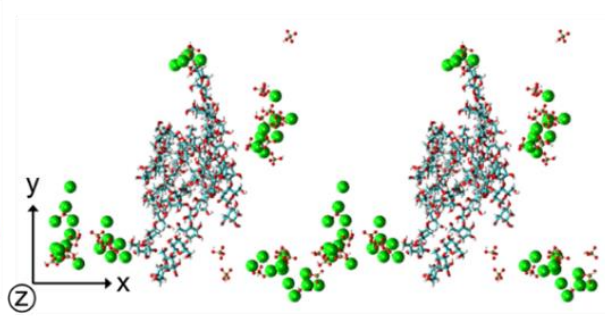

(c) Simulation time (400 ns)

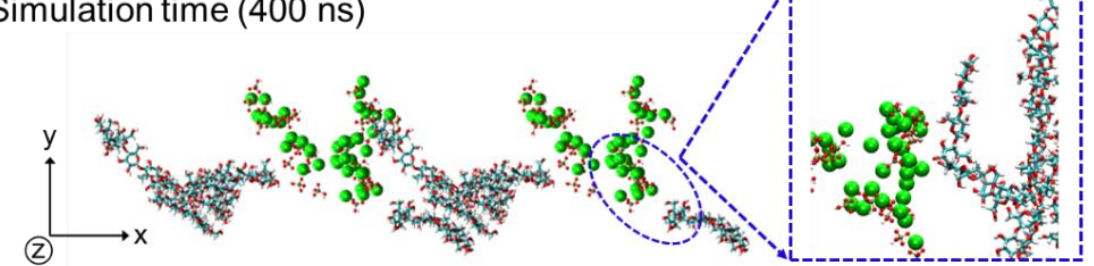

Figure S16. Snapshots (mirrored the x direction) of explicit illustration of all ions and water molecules as a function of simulation time $0 \mathrm{~ns}$ (a), $200 \mathrm{~ns}$ (b) and $400 \mathrm{~ns}$ (c), only cellulose molecule, $\mathrm{Ca}^{2+}$ and $\mathrm{HPO}_{4}{ }^{2-}$ ions are depicted. $\mathrm{HCO}_{3}{ }^{-}$ions, $\mathrm{Mg}^{2+}$ ions, $\mathrm{Na}^{+}$ions and water molecules are not shown for clarity. 


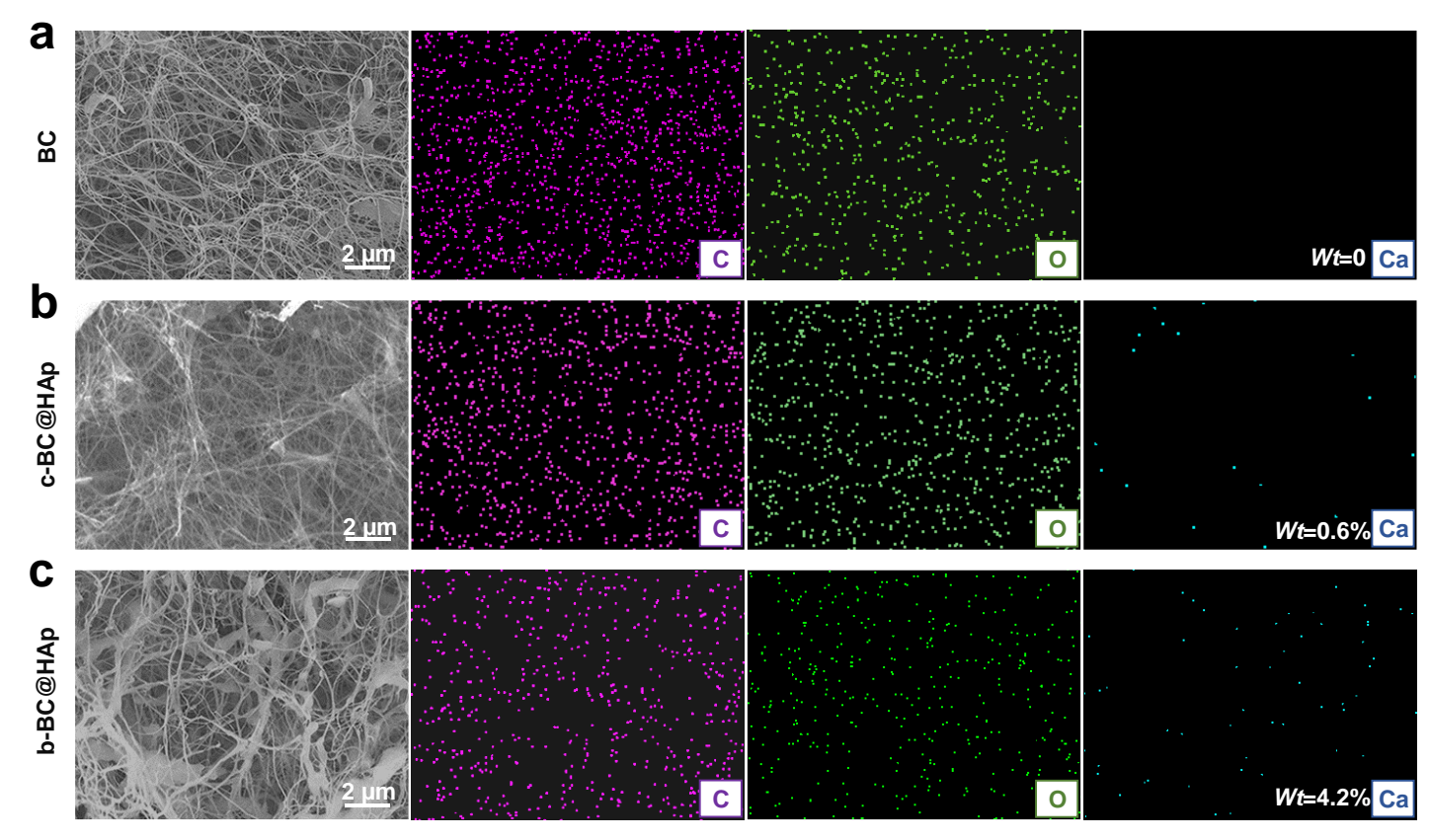

Figure S17. The SEM global view images and the corresponding elemental mapping of BC (a), c-BC@HAp (b) and b-BC@HAp (c) nanofibers after the dissolution of surface HAp by HCl; The EDS results show that in b-BC@HAp composite, large quantities of Ca elemental are captured by BC nanofiber. 

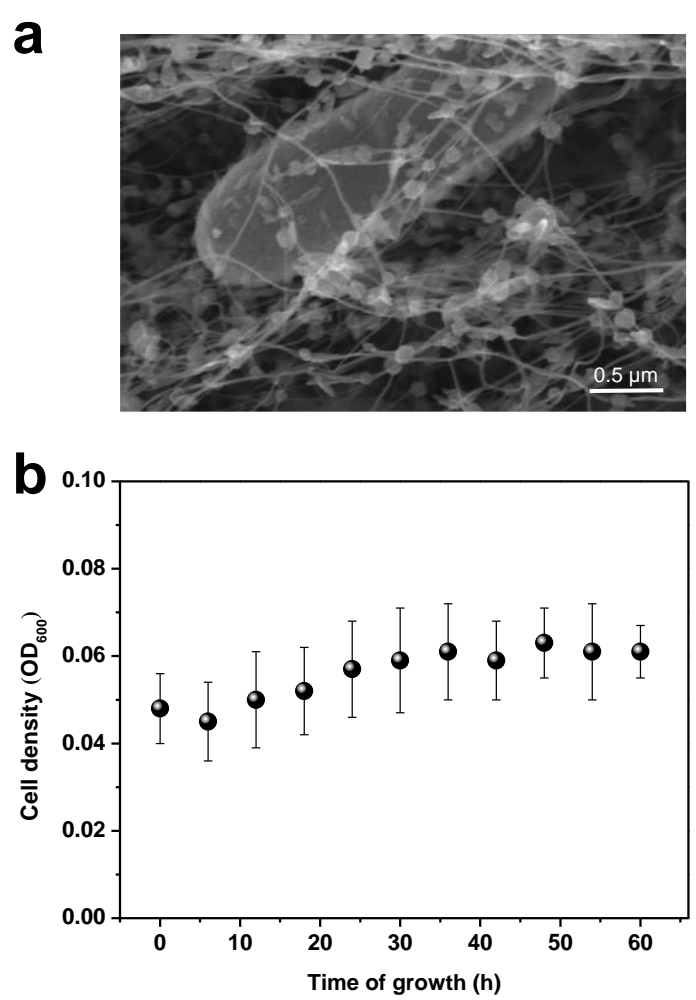

Figure S18. The morphology and growth of bacterial during the formation of HAp under the biological metabolism conditions. (a) SEM image of A.x. cell under the biological metabolism conditions; (b) The cell density of A.x. cell under the biological metabolism conditions, before test, the metabolism solution was treated by $1 \mathrm{mM} \mathrm{HCl}$ and $0.2 \%$ cellulase ( $2 \%$ dissolved in citric acid buffer, and filter by $0.45 \mu \mathrm{m}$ membrane) to remove the excess HAp and nanocellulose, and then washed thoroughly with deionized water three times. 


\section{Supporting Tables}

Table S1. Chemical Composition of Simulated Body Fluid (SBF) Solution

\begin{tabular}{lll}
\hline Order & Reagent & Amount $(\mathrm{g} / \mathrm{L})$ \\
\hline 1 & $\mathrm{NaCl}$ & 142.0 \\
2 & $\mathrm{NaHCO}_{3}$ & 103.0 \\
3 & $\mathrm{KCl}$ & 27.0 \\
4 & $\mathrm{Na}_{2} \mathrm{HPO}_{4} \cdot 2 \mathrm{H}_{2} \mathrm{O}$ & 5.0 \\
5 & $\mathrm{MgCl}_{2} \cdot 6 \mathrm{H}_{2} \mathrm{O}$ & 1.5 \\
6 & $\mathrm{CaCl}_{2} \cdot 2 \mathrm{H}_{2} \mathrm{O}$ & 2.5 \\
7 & $\mathrm{Na}_{2} \mathrm{SO}_{4}$ & 1.0 \\
8 & $\left(\mathrm{CH}_{2} \mathrm{OH}\right)_{3} \mathrm{CNH}_{2}$ & 0.5 \\
\hline
\end{tabular}


Table S2. The calculated mass ratio of HAp to BC by TGA.

\begin{tabular}{cc}
\hline Samples & Mass ratio $\left(m_{\mathrm{HAp}} / m_{\mathrm{BC}}\right)$ \\
\hline b-BC@HAp-12h & 0.23 \\
b-BC@HAp-24h & 1.17 \\
b-BC@HAp-48h & 2.09 \\
\hline
\end{tabular}


Table S3. The binding strength of $\mathrm{Ca}^{2+}$ with the variously located hydroxide radical in BC.

\begin{tabular}{cc}
\hline Species & Gbind $(\mathrm{kcal} / \mathrm{mol})$ \\
\hline $6 \mathrm{glc} 1-\mathrm{Ca}$ & -14.05 \\
$6 \mathrm{glc} 2-\mathrm{Ca}$ & -15.55 \\
$6 \mathrm{glc} 3-\mathrm{Ca}$ & -11.69 \\
$6 \mathrm{glc} 6-\mathrm{Ca}$ & -17.55 \\
$\mathrm{O}_{3}-\mathrm{H}_{6}$ & -1.96 \\
\hline
\end{tabular}


Table S4. The calculated binding free energies (Gbind, $\mathrm{kcal} / \mathrm{mol}$ ) of different compouds at the level of DFT/M062X/6-311+g(d,p) with the implicit solvation model $(\mathrm{PCM})^{10}$.

\begin{tabular}{ccc}
\hline Ions & $\mathrm{Ca}^{2+}$ & $\mathrm{Mg}^{2+}$ \\
\hline $\mathrm{HPO}_{4}{ }^{2-}$ & -17.67 & 2.26 \\
$\mathrm{HCO}_{3}{ }^{-}$ & -13.48 & 2.25 \\
\hline
\end{tabular}


Table S5. The calculated binding free energies-Gbind ( $\mathrm{kcal} / \mathrm{mol})$ of different compounds in gas phase.

\begin{tabular}{ccc}
\hline Ions & $\mathrm{Ca}^{2+}$ & $\mathrm{Mg}^{2+}$ \\
\hline $\mathrm{HPO}_{4}{ }^{2-}$ & -311.30 & -305.20 \\
$\mathrm{HCO}_{3}^{-}$ & -264.17 & -272.39 \\
\hline
\end{tabular}


Table S6. The number of water molecules and ions, and the length of the water box in the last frame configuration of different models.

\begin{tabular}{|c|c|c|c|c|c|c|c|c|c|}
\hline \multirow[b]{2}{*}{ Systems } & \multirow[b]{2}{*}{ Label } & \multicolumn{2}{|l|}{ Cellulo } & \multicolumn{2}{|c|}{ Ions } & \multirow[b]{2}{*}{$\mathrm{Mg}^{2+}$} & \multirow[b]{2}{*}{$\mathrm{Na}^{+}$} & \multirow[b]{2}{*}{ Water } & \multirow[b]{2}{*}{$\operatorname{Box}(\AA)$} \\
\hline & & & $\mathrm{HPO}_{4}{ }^{2-}$ & $\mathrm{HCO}_{3}^{-}$ & $\mathrm{Ca}^{2+}$ & & & & \\
\hline \multirow{2}{*}{ Figure } & without cellulose + & & & & & & & & $a=45.24$ \\
\hline & $10 \mathrm{Ca}^{2+}+5 \mathrm{HPO}_{4}{ }^{2-}$ & 0 & 5 & 50 & 10 & 8 & 24 & 1461 & $\mathrm{~b}=32.28$ \\
\hline S11 & & & & & & & & & $\mathrm{c}=31.05$ \\
\hline \multirow{3}{*}{$\begin{array}{c}\text { Figure } \\
\text { S12 }\end{array}$} & cellulose $+10 \mathrm{Ca}^{2+}+$ & & & & & & & & $a=46.78$ \\
\hline & $5 \mathrm{HPO}_{4}^{2-}$ & 1 & 5 & 50 & 10 & 8 & 24 & 1463 & $\mathrm{~b}=31.34$ \\
\hline & & & & & & & & & $\mathrm{c}=31.41$ \\
\hline \multirow{3}{*}{$\begin{array}{c}\text { Figure } \\
\text { S13 }\end{array}$} & cellulose $+20 \mathrm{Ca}^{2+}$ & & & & & & & & $a=50.90$ \\
\hline & $+15 \mathrm{HPO}_{4}{ }^{2-}$ & 1 & 15 & 50 & 20 & 8 & 24 & 1457 & $\mathrm{~b}=31.29$ \\
\hline & & & & & & & & & $c=29.27$ \\
\hline \multirow{3}{*}{$\begin{array}{c}\text { Figure } \\
\text { S14 }\end{array}$} & cellulose $+20 \mathrm{Ca}^{2+}+$ & & & & & & & & $a=47.59$ \\
\hline & $15 \mathrm{HPO}_{4}{ }^{2-}$ (larger & 1 & 15 & 50 & 20 & 8 & 24 & 2631 & $\mathrm{~b}=43.91$ \\
\hline & box) & & & & & & & & $\mathrm{c}=38.69$ \\
\hline
\end{tabular}




\section{References}

1. Tas, A. C. Synthesis of biomimetic Ca-hydroxyapatite powders at $37 \mathrm{C}$ in synthetic body Fluids. Biomaterials 2000, 21, 1429-1438.

2. Park, S.; Park, J.; Jo, I.; Cho, S.-P.; Sung, D.; Ryu, S.; Park, M.; Min, K.-A.; Kim, J.; Hong, S.; Hong, B. H.; Kim, B.-S. In situ hybridization of carbon nanotubes with bacterial cellulose for three-dimensional hybrid bioscaffolds. Biomaterials 2015, 58, 93-102.

3. Frisch, M. J.; Trucks, G. W.; Schlegel, H. B.; Scuseria, G. E.; Robb, M. A.; Cheeseman, J. R.; Scalmani, G.; Barone, V.; Petersson, G. A.; Nakatsuji, H.; Li, X.; Caricato, M.; Marenich, A. V.; Bloino, J.; Janesko, B. G.; Gomperts, R.; Mennucci, B.; Hratchian, H. P.; Ortiz, J. V.; Izmaylov, A. F.; Sonnenberg, J. L.; Williams-Young, D.; Ding, F.; Lipparini, F.; Egidi, F.; Goings, J.; Peng, B.; Petrone, A.; Henderson, T.; Ranasinghe, D.; Zakrzewski, V. G.; Gao, J.; Rega, N.; Zheng, G.; Liang, W.; Hada, M.; Ehara, M.; Toyota, K.; Fukuda, R.; Hasegawa, J.; Ishida, M.; Nakajima, T.; Honda, Y.; Kitao, O.; Nakai, H.; Vreven, T.; Throssell, K.; Montgomery, J. A., Jr.; Peralta, J. E.; Ogliaro, F.; Bearpark, M. J.; Heyd, J. J.; Brothers, E. N.; Kudin, K. N.; Staroverov, V. N.; Keith, T. A.; Kobayashi, R.; Normand, J.; Raghavachari, K.; Rendell, A. P.; Burant, J. C.; Iyengar, S. S.; Tomasi, J.; Cossi, M.; Millam, J. M.; Klene, M.; Adamo, C.; Cammi, R.; Ochterski, J. W.; Martin, R. L.; Morokuma, K.; Farkas, O.; Foresman, J. B.; Fox, D. J. Gaussian, Inc., Wallingford CT, 2016., Gaussian 16. 2016.

4. Case DA; Betz RM; Cerutti DS, C. I. T., DardenTA, Duke RE, Giese TJ, Gohlke H, Goetz AW, Homeyer N,Izadi S, Janowski P, Kaus J, Kovalenko A, Lee TS, LeGrandS, Li P, Lin C, Luchko T, Luo R, Madej B, Mermelstein D,Merz KM, Monard G, Nguyen H, Nguyen HT, Omelyan I,Onufriev A, Roe DR, Roitberg A, Sagui C, Simmeling CL,Botello-Smith WM, Swails J, Walker RC, Wang J, Wolf RM,Wu X, Xiao L, Kollman PA (2016) AMBER 2016. Universityof California, San Francisco.

5. Bayly, C. I.; Cieplak, P.; Cornell, W.; Kollman, P. A. A well-behaved electrostatic potential based method using charge restraints for deriving atomic charges: the RESP model. J. Phys. Chem 1993, 97, (40), 10269-10280.

6. Wu, X.; Brooks, B. R. Self-guided Langevin dynamics simulation method. Chem. Phys. Lett. 2003, 381, (3-4), $512-$ 518.

7. Svensson, A.; Nicklasson, E.; Harrah, T.; Panilaitis, B.; Kaplan, D.; Brittberg, M.; Gatenholm, P. Gatenholm, P., Bacterial Cellulose As a Potential Scaffold for Tissue Engineering of Cartilage. Biomaterials 2005, 26, (4), 419-431.

8. Dugan, J. M.; Gough, J. E.; Eichhorn, S. J. Directing the Morphology and Differentiation of Skeletal Muscle Cells Using Oriented Cellulose Nanowhiskers. Biomacromolecules 2010, 11, (9), 2498-2504.

9. Hanelt, M.; Gareis, M.; Kollarczik, B. Cytotoxicity of Mycotoxins Evaluated by the MTT-cell Culture Assay. Mycopathologia 1994, 128, (3), 167-174.

10. Kan, Z.; Zhu, Q.; Yang, L.; Huang, Z.; Jin, B.; Ma, J. Polarization effects on the cellulose dissolution in ionic liquids: Molecular dynamics simulations with polarization model and integrated tempering enhanced sampling method. J. Phys. Chem. B 2017, 121, (17), 4319-4332. 